\title{
Repurposing antipsychotics as glioblastoma therapeutics: Potentials and challenges (Review)
}

\author{
JIN-KU LEE ${ }^{1}$, DO-HYUN NAM ${ }^{1}$ and JEONGWU LEE ${ }^{2}$ \\ ${ }^{1}$ Cancer Stem Cell Research Center, Department of Neurosurgery, \\ Samsung Medical Center and Samsung Biomedical Research Institute, Sungkyunkwan University School of Medicine, \\ Seoul 135-710, Republic of Korea; ${ }^{2}$ Department of Stem Cell Biology and Regenerative Medicine, \\ Lerner Research Institute, Cleveland Clinic, Cleveland, OH 44195, USA
}

Received September 17, 2014; Accepted May 29, 2015

DOI: $10.3892 / \mathrm{ol} .2016 .4074$

\begin{abstract}
Glioblastoma multiforme (GBM) is the most common and most lethal primary brain tumor, with tragically little therapeutic progress over the last 30 years. Surgery provides a modest benefit, and GBM cells are resistant to radiation and chemotherapy. Despite significant development of the molecularly targeting strategies, the clinical outcome of GBM patients remains dismal. The challenges inherent in developing effective GBM treatments have become increasingly clear, and include resistance to standard treatments, the blood-brain barrier, resistance of GBM stem-like cells, and the genetic complexity and molecular adaptability of GBM. Recent studies have collectively suggested that certain antipsychotics harbor antitumor effects and have potential utilities as anti-GBM therapeutics. In the present review, the anti-tumorigenic effects and putative mechanisms of antipsychotics, and the challenges for the potential use of antipsychotic drugs as anti-GBM therapeutics are reviewed.
\end{abstract}

\section{Contents}

1. Introduction

2. Anti-neoplastic effects of antipsychotics

3. Antipsychotics as anti-GBM therapeutics

4. GPCR blockers in cancer

5. Conclusion

Correspondence to: Dr Jeongwu Lee, Department of Stem Cell Biology and Regenerative Medicine, Lerner Research Institute, Cleveland Clinic, 9500 Euclid Avenue, Cleveland, OH 44195, USA E-mail: leej7@ccf.org

Dr Do-Hyun Nam, Cancer Stem Cell Research Center, Department of Neurosurgery, Samsung Medical Center and Samsung Biomedical Research Institute, Sungkyunkwan University School of Medicine, 188-1 Ilwon-dong, Kangnam, Seoul 135-710, Republic of Korea E-mail: nsnam@skku.edu

Key words: antipsychotics, glioblastoma, therapy

\section{Introduction}

Glioblastoma multiforme (GBM) is the most common and most malignant type of brain cancer. Despite extensive efforts over the past decades, the prognosis for GBM patients remains dismal. The median survival time of GBM patients is currently 14.6 months from diagnosis, which is only a few months longer compared with 30 years ago. The five-year overall survival rate of GBM is $<10 \%$ (1). Currently, the standard-of-care for the majority of GBM patients is a combination of surgical resection, radiation and chemotherapy with temozolomide (TMZ) (2-4). However, this aggressive treatment provides only palliation.

There are several factors to limit clinical improvements against this devastating disease. First, molecularly targeted agents with demonstrated therapeutic benefits in other types of cancer have shown minimal or no efficacy against GBM (5). For example, bevacizumab, a neutralizing antibody against vascular endothelial growth factor, is effective in treating certain cancers, including metastatic colon cancer and non-small cell lung cancer (NSCLC). By contrast, recent large-scale clinical trials with bevacizumab have achieved no improvement in the overall survival of newly diagnosed GBM patients (6,7). Epidermal growth factor receptor (EGFR) is frequently activated in GBM, as $40-60 \%$ of GBM tumors have genomic amplifications and/or activating mutations of the EGFR gene. The first-generation small-molecule EGFR inhibitors, such as gefitinib, have performed poorly against GBM in several clinical trials (8-10). While the Bcr-Abl-targeting drug imatinib revealed notable efficacy for patients with chronic myeloid leukemia, clinical trials of imatinib in GBM have failed to demonstrate any therapeutic advantages (11-13). Finally, dasatinib, a platelet-derived growth factor and Src inhibitor failed to show benefit in recurrent GBM patients, either alone or in combination with bevacizumab (14).

The low distribution of systemically administrated chemotherapeutics within the brain represents a significant challenge in treating GBM. The blood-brain barrier (BBB) restricts delivery of therapeutic compounds, particularly for large molecules and hydrophilic drugs. The BBB can be compromised at the core of a GBM tumor, however, it is generally intact at the invading edges of the tumor. In addition, other 
factors, such as a distinct immune system in the brain and interstitial pressure, limit the retention of drugs in the tumor. Concentrations of systemically administered antineoplastic drugs were reported to be significantly low in glioma tissues compared with blood (15). Thus, certain drugs that may otherwise be effective against GBM fail to show efficacy simply due to their low permeabilities or low retention capacities in the brain.

Recently, the strategies of utilizing the existing drugs for other diseases, known as 'drug repositioning' or 'drug repurposing,' have been extensively investigated as a method of drug discovery. The use of existing FDA-approved drugs can bypass or shorten critical steps of drug development, such as chemical optimization and toxicology testing, thereby resulting in a shorter time frame for clinical translation (16).

Antipsychotics deserve particular scrutiny as potential therapies for GBM. Antipsychotic drugs such as pimozide, $\mathrm{N}$-methyl-D-aspartate receptor (NMDAR) agonists/antagonists, $\gamma$-aminobutyric acid inhibitors and valproic acids are frequently prescribed for the management of various psychiatric disorders, including schizophrenia, acute/chronic psychosis, delusional disorders, depression and anxiety disorder (17-20). These drugs have a long history of clinical use and tolerable safety in humans, and readily penetrate the $\mathrm{BBB}$, which is particularly important for GBM (21). In the present review, an overview of various preclinical and clinical studies testing the efficacy of antipsychotics for the treatment of human malignancies, including GBM, is presented and the putative mechanisms for the anti-neoplastic actions of these antipsychotic drugs is reviewed.

\section{Anti-neoplastic effects of antipsychotics}

Antipsychotic drugs have been used for decades in various psychiatric clinical settings, and have tolerable or low toxicities and well-characterized profiles of sequelae. Due to the established safety of these drugs, combined with their proven ability to cross the BBB, antipsychotic medications are increasingly being tested for efficacy in patients with various cancers, including malignant brain tumors. Furthermore, epidemiological studies with diverse patient populations have reported significantly lower incidences of cancer among patients with schizophrenia compared with the general population (22-29). These findings support the possibility that antipsychotics may partially ameliorate the risk of cancer development, although molecular elucidations are yet to be accomplished.

Valproic acid has been approved for the treatment of psychiatric disorders such as bipolar disorder and schizophrenia. The anti-neoplastic properties of valproic acid have been demonstrated in leukemia and several solid tumors. One of the most well-studied molecular targets of valproic acid is the histone deacetylases (HDACs). Histone acetylation and deacetylation are epigenetic mechanisms that control gene expression via histone modification leading to the changes in chromatin structure. The overexpression and increased activity of HDACs have been reported in the stages of tumor initiation and progression (30-34).

Another antipsychotic drug that has shown encouraging results in several different types of cancer is pimozide. Pimozide has been used to treat psychiatric disorders for over
50 years. Pimozide inhibits the proliferation of breast cancer cells and significantly increases the sensitivity of tumor cells to $\gamma$-irradiation (35-37). The observed growth inhibition and radio-sensitization are believed to be due to inhibition of $\sigma$-receptors, which are atypical $\mathrm{G}$ protein-coupled receptors (GPCRs). Additionally, pimozide has been shown to exhibit promising activity in patients with metastatic melanoma (38). Pimozide also inhibits the activity of a deubiquitination complex, ubiquitin-specific protease 1 (USP1)/USP-associated factor 1 (39).

In addition, a number of psychiatric drugs have shown promising results in pre-clinical studies, although they have not yet demonstrated efficacy in human clinical trials. For example, the antipsychotic drug thioridazine selectively impaired the in vivo tumorigenicity of neoplastic pluripotent stem cells (40). It was reported that several antipsychotics, including phenothiazines, have anti-proliferative properties against various tumor cell lines, including neuorblastoma, non-small cell lung cancer, glioma and melanoma, which indicates that antipsychotics may be useful for adjuvant chemotherapeutic regimens (41). Drori et al showed that antipsychotics such as reserpine notably potentiated taxol- or anthracycline-associated cytotoxicity in human nasopharyngeal carcinoma cells (42). In another study, Haloperidol, a typical antipsychotic drug, augmented the cytotoxic effect of vinblastine, idarubicin and cisplatin in vinblastine-resistant human leukemia cells (43).

Wiklund et al tested the anticancer properties of six antipsychotics: Reserpine, chlorpromazine, haloperidol, pimozide, risperidone and olanzapine. All these drugs, with the exception of risperidone, showed selective growth inhibition of various cancer cell lines derived from lymphoblastoma, neuroblastoma, NSCLC and breast adenocarcinoma (44). In another multi-drug screening study, the antipsychotic drug class of the phenothiazines, consisting of chloropromazine, levomepromazine, promethazine, trifluoperazine and thioridazine, displayed notable anti-proliferative and selective cytotoxic properties against various leukemia cell lines (45). Evidence to justify further investigation of drugs that modulate muscarinic receptor signals as anti-neoplastic therapies came from a recent study that examined the role of the autonomic nervous system (i.e. sympathetic and parasympathetic signals) in the development of cancer (46). The NMDAR pathway contributes to the pathogenesis of multiple human cancers, including pancreatic ductal carcinoma, breast cancer, ovarian cancer and glioma, and is associated with the poor prognosis of patients with those cancers. For example, MK-801, an NMDAR antagonist and potential antidepressant, displayed therapeutic efficacy in cultured cancer cells and tumor-bearing mice (47). In summary, a series of studies have reported the anti-tumorigenic effects of various antipsychotics, although further investigation is required to determine the precise molecular targets and mechanisms of these drugs.

\section{Antipsychotics as anti-GBM therapeutics}

Valproic acid was first tested 15 years ago to evaluate its efficacy against pediatric malignant gliomas (33). Since then, several studies have provided support to the hypothesis that valproic acid derivatives are a promising drug class for the treatment of GBM. Valproic acid attenuated the growth of 
glioma cells by inhibiting angiogenesis (48) and inducing differentiation (49). In addition, valproic acid increased the sensitivity of glioma cells to conventional GBM therapies, including TMZ and $\gamma$-radiation $(50,51)$.

As implied by its name, GBM harbors profound intra-tumoral heterogeneity. The cancer stem cell hypothesis posits the cellular hierarchy in which a subpopulation of highly tumorigenic, stem-like cells resides at the apex. While certain cancers may not follow cancer stem cell models, numerous studies support that the fact that the majority of GBMs harbor GBM stem-like cells (GSCs). GSCs share a number of characteristics with normal neural stem/progenitor cells, most notably a self-renewal capacity and potential for multi-lineage differentiation. As GSCs are enriched with tumor initiation/propagation capacities, and as they are phenotypically resistant to radiotherapy and chemotherapy, potential curative GBM therapies may require the targeting of GSCs, as well as the bulk of the tumor (52-61). Considering the cancer stem cell concept, Diamandis et al (62) screened 1,267 chemical compounds to identify molecules that inhibit the clonogenic growth of neural cells (59). Notably, several potent compounds were identified through this screen, including a number of dopamine receptor modulators (butaclamol, apomorphins and flupenthixol), an NMDA receptor antagonist (lifenprodil), an opioid receptor agonist (carbetapentane) and serotonin receptor agonists (62). Another chemical screening using embryonic stem cells and its derivative cancer cells showed that a dopamine receptor antagonist potently impaired the tumor formation capability of cancer stem cells (40). The phenothiazine class includes drugs such as thioridazine, fluphenazine or perphenazine, and is known to antagonize dopamine signaling. The anti-glioma effects of phenothiazines have been reported (63). Tricyclic neuroleptic drugs, such as chlorpromazine, promoted autophagic cell death in the PTEN-null U-87MG glioma cell line by inhibiting the PI3K/AKT/mTOR pathway (64). In addition, antipsychotics, such as paliperidone, pimozide and risperidone, which are selective $5-\mathrm{HT}_{7}$ inhibitors, have been studied for their potential use as an adjuvant chemotherapy in the management of GBM (65).

\section{GPCR blockers in cancer}

GPCRs transmit multiple biological signals through a heterotrimeric $G$ protein associated with the inner surface of the plasma membrane (66). The heterotrimeric $G$ proteins, which are composed of $\mathrm{Ga}(\mathrm{G}-\alpha), \mathrm{Gb}(\mathrm{G}-\beta)$ and $\mathrm{Gc}(\mathrm{G}-\gamma)$ subunits, are bound to guanosine diphosphate (GDP) when they are inactive. Upon activation, GDP is replaced by guanosine triphosphate (GTP), resulting in subunit dissociation into a $\beta \gamma$ dimer and the GTP-bound $\alpha$-monomer (67). The Ga subunit is classified into four families: $\mathrm{Ga}_{\mathrm{s}}, \mathrm{Ga}_{\mathrm{i}}, \mathrm{Ga}_{\mathrm{q}}$ and $\mathrm{Ga}_{12}$. Each $\mathrm{Ga}$ family can transmit different downstream signals, thereby affecting diverse biological functions (68). Despite the biological significance of GPCRs in tumorigenesis, selective GPCR-targeted anticancer drugs are few. The rarity of GPCRs as cancer therapies is rather striking considering that GPCRs are targeted by $25 \%$ of top-selling drugs, including $\beta$-blockers, antipsychotics and analgesics (69). Typical antipsychotics, such as chlopromazine and haloperidol, were discovered in the 1950s. Although they are clinically effective, side-effects such as extrapyramidal symptom (EPS) and hyperprolactinemia have limited their chronic application. The more recently developed 'atypical' antipsychotics, such as clozapine, show comparable efficacy to the typical drugs, but without EPS (70,71).

The majority of antipsychotic drugs bind to dopamine receptors, antagonizing this signaling pathway in striatal cells (72). However, antipsychotics also have significant affinity for other GPCRs, including serotonin 5-HT ${ }_{1 \mathrm{~A}}$, $\alpha$-adrenergic receptors and muscarinic receptors (73). Atypical antipsychotics regulate $\mathrm{G}_{\mathrm{i}}$ and $\mathrm{G}_{\mathrm{q}}$ activity by modulating the function of serotonergic $2 A R$ and the $G_{i}$-linked GPCR metabotropic glutamate 2 receptor heterodimeric complex (74). A cell-based functional assay to identify the pharmacological profile of 40 clinically useful antipsychotics revealed that almost all antipsychotics are potent inverse agonists of the $5-\mathrm{HT}_{2 \mathrm{~A}}$ receptor, a monoamine GPCR, as well as effective dopamine D2 receptor antagonists (75). A recent study demonstrated that clozapine and risperidone have activity at more than a dozen monoamine GPCRs (76). These findings collectively indicate that antipsychotics have high affinity and selectivity for GPCRs, but have low specificity among the GPCR superfamily.

Abnormal activation of GPCRs by unusually high levels of bio-active lipids, such as lysophosphatidic acid or sphingosine-1-phosphate, leads to expression of various cancer-associated genes involved in cell survival, proliferation, migration and angiogenesis (77-79). In addition, endothelin receptors, GPCRs that are upregulated in several types of cancer, regulate cell survival, angiogenesis, invasion, metastasis and epithelial-to-mesenchymal transition (80). Seven-transmembrane Frizzled family receptors and the co-receptor lipoprotein receptor-related protein are other GPCRs that initiate signaling within the canonical Wnt pathway, thus contributing to the development and progression of cancer (81-83). The Wnt/ $\beta$-catenin signaling pathway plays a crucial role in the development of GBM by promoting glioma proliferation, invasion and GSC formation (84-86). Hedgehog $(\mathrm{Hh})$ signaling is another key component in the tumorigenesis of multiple malignancies $(87,88)$. Smoothened (Smo), a seven-span transmembrane GPCR, is a key transducer of Hh signaling (89). Aberrant Hh pathway activation by the mutation of Smo is associated with the development of several cancers, including basal cell carcinoma and medulloblastoma (90). Ligand-dependent $\mathrm{Hh}$ pathway activation is involved in the tumorigenesis of gastrointestinal cancer, prostate tumors and glioma $(91,92)$.

CXC chemokine receptors are another family of GPCRs that are indicated to be involved in tumorigenesis. Besides their roles in leukocyte chemotaxis, CXC chemokine receptors play an important role in cancer cell survival, proliferation and angiogenesis (93-96). The prominent expression of CXCR4, a G protein-coupled chemokine receptor, and its ligand, stromal cell-derived factor- $1 \alpha$, result in the activation of MAPK and Akt, leading to enhanced survival in glioma cells (97). In addition, overexpressed CXCR4 is associated with an invasive phenotype in malignant glioma (98). Additionally, glioma stem-like cells promote angiogenesis via the CXCR4/CXCL12 signaling pathway (99). 
Amongst the GPCRs, dopamine receptors are particularly notable target molecules for therapies aimed at cancer stem cells (40). Dopamine receptors are predominant in the central nervous system (CNS), and participate in various neurological processes, including motivation, cognition, memory and fine motor control (100). A recent study demonstrated that polymorphism of the dopamine receptor D2 is associated with the colorectal cancer risk, suggesting that an analogous situation could apply in CNS tumorigenesis (101). On the other hand, dopamine signaling enhances the efficacy of anticancer therapy in breast and colon cancer cell lines (102). In addition, the balance of peripheral dopamine signals is critical in tumor growth (103). Signaling via 5- $\mathrm{HT}_{7}$, a relatively specific GPCR within the human nervous system, promotes the activation of extracellular signal-regulated kinases and STAT3, resulting in tumor survival and proliferation (65).

\section{Conclusion}

The dismal prognosis of GBM highlights the urgent requirement for the development of drugs with novel mechanisms of action. Of all the classes of drugs that affect brain function, antipsychotics have the longest history of clinical use, and comprise some of the most frequently prescribed drugs in the world. A growing body of evidence suggests that several antipsychotics display significant anti-neoplastic effects on multiple human cancers. For example, valproic acid attenuates cancer cell proliferation by inhibiting HDACs. Therefore, antipsychotic drugs may represent strong candidates for chemotherapeutic adjuvants in the treatment of GBM due to their clinically proven safety and accumulation in the brain, along with their anti-neoplastic efficacy.

One potential concern with the use of antipsychotics in cancer treatment is the possibility of unexpected adverse effects. Despite their long history of clinical application and a reliable safety profile, typical and atypical antipsychotics are known to cause a wide range of side-effects (104). The majority of antipsychotics induce CNS side-effects, such as sedation, headaches, dizziness and diarrhea in up to $50 \%$ of patients (105). More seriously, the extrapyramidal side-effects of typical antipsychotic drugs, including akathisia, dystonia and drug-induced secondary Parkinsonism, may prevent their chronic use (71). Second-generation atypical antipsychotics can also cause metabolic problems, such as obesity and type II diabetes (106). Thus, optimization of drug structures may be required to avoid adverse side-effects if the anti-tumorigenic effect of a given drug is proven.

\section{Acknowledgements}

This review was supported by a grant from the Korea Health Technology R\&D project through the Korea Health Industry Development Institute, funded by the Ministry of Health and Welfare, Republic of Korea (no. HI09C1552), the Global Frontier Project grant (no. NRF-2012M3A6A-2010-00297 81) of National Research Foundation funded by the Ministry of Science, ICT and Future Planning of Korea, the Samsung Medical Center grant (no. GFO1140011), and the National Institutes of Health (nos. R01 NS082312 and R01 NS083767).

\section{References}

1. Ostrom QT, Gittleman H, Farah P, Ondracek A, Chen Y, Wolinsky Y, Stroup NE, Kruchko C and Barnholtz-Sloan JS: CBTRUS statistical report: Primary brain and central nervous system tumors diagnosed in the United States in 2006-2010. Neuro Oncol (15 Suppl 2): ii1-ii56, 2013.

2. Ostermann S, Csajka C, Buclin T, Leyvraz S, Lejeune F, Decosterd LA and Stupp R: Plasma and cerebrospinal fluid population pharmacokinetics of temozolomide in malignant glioma patients. Clin Cancer Res 10: 3728-3736, 2004.

3. Laperriere N, Zuraw L and Cairncross G; Cancer Care Ontario Practice Guidelines Initiative Neuro-Oncology Disease Site Group: Radiotherapy for newly diagnosed malignant glioma in adults: A systematic review. Radiother Oncol 64: 259-273, 2002.

4. Stupp R, Mason WP, van den Bent MJ, et al: Radiotherapy plus concomitant and adjuvant temozolomide for glioblastoma. $\mathrm{N}$ Engl J Med 352: 987-996, 2005.

5. Ohka F, Natsume A and Wakabayashi T: Current trends in targeted therapies for glioblastoma multiforme. Neurol Res Int 2012: 878425, 2012.

6. Keunen O, Johansson M, Oudin A, Sanzey M, Rahim SA Fack F, Thorsen F, Taxt T, Bartos M, Jirik R, et al: Anti-VEGF treatment reduces blood supply and increases tumor cell invasion in glioblastoma. Proc Natl Acad Sci USA 108: 3749-3754, 2011.

7. Chinot OL, Wick W, Mason W, Henriksson R, Saran F, Nishikawa R, Carpentier AF, Hoang-Xuan K, Kavan P, Cernea D, et al: Bevacizumab plus radiotherapy-temozolomide for newly diagnosed glioblastoma. N Engl J Med 370: 709-722, 2014.

8. Uhm JH, Ballman KV, Wu W, Giannini C, Krauss JC, Buckner JC, James CD, Scheithauer BW, Behrens RJ, Flynn PJ, et al: Phase II evaluation of gefitinib in patients with newly diagnosed Grade 4 astrocytoma: Mayo/North central cancer treatment group study N0074. Int J Radiat Oncol Biol Phys 80: 347-353, 2011

9. Lau D, Magill ST and Aghi MK: Molecularly targeted therapies for recurrent glioblastoma: Current and future targets. Neurosurg Focus 37: E15, 2014.

10. Melosky B: Review of EGFR TKIs in metastatic NSCLC, including ongoing trials. Front Oncol 4: 244, 2014.

11. Wen PY, Yung WK, Lamborn KR, Dahia PL, Wang Y, Peng B Abrey LE, Raizer J, Cloughesy TF, Fink K, et al: Phase I/II study of imatinib mesylate for recurrent malignant gliomas: North American brain tumor consortium study 99-08. Clin Cancer Res 12: 4899-4907, 2006

12. Razis E, Selviaridis P, Labropoulos S, Norris JL, Zhu MJ, Song DD, Kalebic T, Torrens M, Kalogera-Fountzila A, Karkavelas G, et al: Phase II study of neoadjuvant imatinib in glioblastoma: Evaluation of clinical and molecular effects of the treatment. Clin Cancer Res 15: 6258-6266, 2009.

13. Druker BJ, Talpaz M, Resta DJ, Peng B, Buchdunger E, Ford JM, Lydon NB, Kantarjian H, Capdeville R, Ohno-Jones S, et al: Efficacy and safety of a specific inhibitor of the BCR-ABL tyrosine kinase in chronic myeloid leukemia. N Engl J Med 344: 1031-1037, 2001.

14. Lu-Emerson C, Norden AD, Drappatz J, QuantEC, BeroukhimR, Ciampa AS, Doherty LM, Lafrankie DC, Ruland S and Wen PY: Retrospective study of dasatinib for recurrent glioblastoma after bevacizumab failure. J Neurooncol 104: 287-291, 2011.

15. Pitz MW, Desai A, Grossman SA and Blakeley JO: Tissue concentration of systemically administered antineoplastic agents in human brain tumors. J Neurooncol 104: 629-638, 2011.

16. Ashburn TT and Thor KB: Drug repositioning: identifying and developing new uses for existing drugs. Nat Rev Drug Discov 3: 673-683, 2004.

17. Yaryura-Tobias JA, Patito JA, Mizrahi J, Roger RV and Cappelletti SR: The action of pimozide on acute psychosis. Acta Psychiatr Belg 74: 421-429, 1974.

18. Lapidus KA, Soleimani L and Murrough JW: Novel glutamatergic drugs for the treatment of mood disorders. Neuropsychiatr Dis Treat 9: 1101-1112, 2013.

19. Foster AC and Kemp JA: Glutamate- and GABA-based CNS therapeutics. Curr Opin Pharmacol 6: 7-17, 2006.

20. Rosenberg G: The mechanisms of action of valproate in neuropsychiatric disorders: Can we see the forest for the trees? Cell Mol Life Sci 64: 2090-2103, 2007.

21. Javaid JI: Clinical pharmacokinetics of antipsychotics. J Clin Pharmacol 34: 286-295, 1994. 
22. Barak Y, Achiron A, Mandel M, Mirecki I and Aizenberg D Reduced cancer incidence among patients with schizophrenia. Cancer 104: 2817-2821, 2005.

23. Tran E, Rouillon F, Loze JY, Casadebaig F, Philippe A, Vitry F and Limosin F: Cancer mortality in patients with schizophrenia: an 11-year prospective cohort study. Cancer 115: 3555-3562, 2009.

24. Chou FH, Tsai KY, Su CY and Lee CC: The incidence and relative risk factors for developing cancer among patients with schizophrenia: A nine-year follow-up study. Schizophr Res 129: 97-103, 2011.

25. Damjanović A, Ivković M, Jasović-Gasić M and Paunović V: Comorbidity of schizophrenia and cancer: Clinical recommendations for treatment. Psychiatr Danub 18: 55-60, 2006.

26. du Pan RM and Muller C: Cancer mortality in patients of psychiatric hospitals. Schweiz Med Wochenschr 107: 597-604, 1977 (In French).

27. Grinshpoon A, Barchana M, Ponizovsky A, et al: Cancer in schizophrenia: Is the risk higher or lower? Schizophr Res 73: 333-341, 2005.

28. Lichtermann D: Cancer risk in parents of patients with schizophrenia. Am J Psychiatry 162: 1024; author reply 1024-1026, 2005.

29. Goldacre MJ, Kurina LM, Wotton CJ, Yeates D and Seagroat V: Schizophrenia and cancer: An epidemiological study. Br J Psychiatry 187: 334-338, 2005.

30. Michaelis M, Doerr HW and Cinatl J Jr: Valproic acid as anti-cancer drug. Curr Pharm Des 13: 3378-3393, 2007.

31. Duenas-Gonzalez A, Candelaria M, Perez-Plascencia C, Perez-Cardenas E, de la Cruz-Hernandez E and Herrera LA: Valproic acid as epigenetic cancer drug: Preclinical, clinical and transcriptional effects on solid tumors. Cancer Treat Rev 34: 206-222, 2008

32. Reynolds MF, Sisk EC and Rasgon NL: Valproate and neuroendocrine changes in relation to women treated for epilepsy and bipolar disorder: A review. Curr Med Chem 14: 2799-2812, 2007.

33. Driever PH, Knupfer MM, Cinatl J and Wolff JE: Valproic acid for the treatment of pediatric malignant glioma. Klin Padiatr 211: 323-328, 1999.

34. Sami S, Höti N, Xu HM, Shen Z and Huang X: Valproic acid inhibits the growth of cervical cancer both in vitro and in vivo. J Biochem 144: 357-362, 2008.

35. Strobl JS, Melkoumian Z, Peterson VA and Hylton H: The cell death response to gamma-radiation in MCF-7 cells is enhanced by a neuroleptic drug, pimozide. Breast Cancer Res Treat 51: 83-95, 1998.

36. Brimson JM, Brown CA and Safrany ST: Antagonists show GTP-sensitive high-affinity binding to the sigma-1 receptor. $\mathrm{Br}$ J Pharmacol 164: 772-780, 2011.

37. Strobl JS, Kirkwood KL, Lantz TK, Lewine MA, Peterson VA and Worley JF III: Inhibition of human breast cancer cell proliferation in tissue culture by the neuroleptic agents pimozide and thioridazine. Cancer Res 50: 5399-5405, 1990.

38. Neifeld JP, Tormey DC, Baker MA, Meyskens FL Jr and Taub RN: Phase II trial of the dopaminergic inhibitor pimozide in previously treated melanoma patients. Cancer Treat Rep 67: 155-157, 1983.

39. Chen J, Dexheimer TS, Ai Y, Liang Q, Villamil MA, Inglese J, Maloney DJ, Jadhav A, Simeonov A and Zhuang Z: Selective and cell-active inhibitors of the USP1/UAF1 deubiquitinase complex reverse cisplatin resistance in non-small cell lung cancer cells. Chem Biol 18: 1390-1400, 2011.

40. Sachlos E, Risueño RM, Laronde S, Shapovalova Z, Lee JH, Russell J, Malig M, McNicol JD, Fiebig-Comyn A, Graham M, et al: Identification of drugs including a dopamine receptor antagonist that selectively target cancer stem cells. Cell 149 1284-1297, 2012

41. Fond G, Macgregor A, Attal J, et al: Antipsychotic drugs: pro-cancer or anti-cancer? A systematic review. Med Hypotheses 79: 38-42, 2012.

42. DroriS,Eytan GD and Assaraf YG: Potentiation of anticancer-drug cytotoxicity by multidrug-resistance chemosensitizers involves alterations in membrane fluidity leading to increased membrane permeability. Eur J Biochem 228: 1020-1029, 1995.

43. Kataoka Y, Ishikawa M, Miura M, Takeshita M, Fujita R, Furusawa S, Takayanagi M, Takayanagi Y and Sasaki K Reversal of vinblastine resistance in human leukemic cells by haloperidol and dihydrohaloperidol. Biol Pharm Bull 24: 612-617, 2001.
44. Wiklund ED, Catts VS, Catts SV, Ng TF, Whitaker NJ, Brown AJ and Lutze-Mann LH: Cytotoxic effects of antipsychotic drugs implicate cholesterol homeostasis as a novel chemotherapeutic target. Int J Cancer 126: 28-40, 2010.

45. Zhelev Z, Ohba H, Bakalova R, Hadjimitova V, Ishikawa M, Shinohara Y and Baba Y: Phenothiazines suppress proliferation and induce apoptosis in cultured leukemic cells without any influence on the viability of normal lymphocytes. Phenothiazines and leukemia. Cancer Chemother Pharmacol 53: 267-275, 2004.

46. Magnon C, Hall SJ, Lin J, Xue X, Gerber L, Freedland SJ and Frenette PS: Autonomic nerve development contributes to prostate cancer progression. Science 341: 1236361, 2013.

47. Li L and Hanahan D: Hijacking the neuronal NMDAR signaling circuit to promote tumor growth and invasion. Cell 153: 86-100, 2013.

48. Osuka S, Takano S, Watanabe S, Ishikawa E, Yamamoto T and Matsumura A: Valproic acid inhibits angiogenesis in vitro and glioma angiogenesis in vivo in the brain. Neurol Med Chir (Tokyo) 52: 186-193, 2012

49. Berendsen S, Broekman M, Seute T, Snijders T, van Es C, de Vos F, Regli L and Robe P: Valproic acid for the treatment of malignant gliomas: Review of the preclinical rationale and published clinical results. Expert Opin Investig Drugs 21: 1391-1415, 2012.

50. Van Nifterik KA, Van den Berg J, Slotman BJ, Lafleur MV, Sminia P and Stalpers LJ: Valproic acid sensitizes human glioma cells for temozolomide and $\gamma$-radiation. J Neurooncol 107: 61-67, 2012

51. Das CM, Aguilera D, Vasquez H, Prasad P, Zhang M, Wolff JE and Gopalakrishnan V: Valproic acid induces p21 and topoisomerase-II (alpha/beta) expression and synergistically enhances etoposide cytotoxicity in human glioblastoma cell lines. J Neurooncol 85: 159-170, 2007.

52. Singh SK, Hawkins C, Clarke ID, Squire JA, Bayani J, Hide T, Henkelman RM, Cusimano MD and Dirks PB: Identification of human brain tumour initiating cells. Nature 432: 396-401, 2004.

53. Bao S, Wu Q, McLendon RE, Hao Y, Shi Q, Hjelmeland AB, Dewhirst MW, Bigner DD and Rich JN: Glioma stem cells promote radioresistance by preferential activation of the DNA damage response. Nature 444: 756-760, 2006.

54. Bao S, Wu Q, Sathornsumetee S, Hao Y, Li Z, Hjelmeland AB, Shi Q, McLendon RE, Bigner DD and Rich JN: Stem cell-like glioma cells promote tumor angiogenesis through vascular endothelial growth factor. Cancer Res 66: 7843-7848, 2006.

55. Das S, Srikanth M and Kessler JA: Cancer stem cells and glioma. Nat Clin Pract Neurol 4: 427-435, 2008.

56. Stiles CD and Rowitch DH: Glioma stem cells: a midterm exam. Neuron 58: 832-846, 2008.

57. Fine HA: Glioma stem cells: Not all created equal. Cancer Cell 15: 247-249, 2009

58. Feng X, Zhou Q, Liu C and Tao ML: Drug screening study using glioma stem-like cells. Mol Med Rep 6: 1117-1120, 2012

59. Lee J, Kotliarova S, Kotliarov Y, Li A, Su Q, Donin NM, Pastorino S, Purow BW, Christopher N, Zhang W, et al: Tumor stem cells derived from glioblastomas cultured in bFGF and EGF more closely mirror the phenotype and genotype of primary tumors than do serum-cultured cell lines. Cancer Cell 9: 391-403, 2006.

60. Joo KM, Jin J, Kim E, Ho Kim K, Kim Y, Gu Kang B, Kang YJ, Lathia JD, Cheong KH, Song PH, et al: MET signaling regulates glioblastoma stem cells. Cancer Res 72: 3828-3838, 2012.

61. Kim E, Kim M, Woo DH, Shin Y, Shin J, Chang N, Oh YT, Kim H, Rheey J, Nakano I, et al: Phosphorylation of EZH2 activates STAT3 signaling via STAT3 methylation and promotes tumorigenicity of glioblastoma stem-like cells. Cancer Cell 23: 839-852, 2013.

62. Diamandis P, Wildenhain J, Clarke ID, Sacher AG, Graham J, Bellows DS, Ling EK, Ward RJ, Jamieson LG, Tyers M, et al: Chemical genetics reveals a complex functional ground state of neural stem cells. Nat Chem Biol 3: 268-273, 2007.

63. Gil-Ad I, Shtaif B, Levkovitz Y, Dayag M, Zeldich E and Weizman A: Characterization of phenothiazine-induced apoptosis in neuroblastoma and glioma cell lines: Clinical relevance and possible application for brain-derived tumors. J Mol Neurosci 22: 189-198, 2004.

64. Shin SY, Lee KS, Choi YK, Lim HJ, Lee HG, Lim Y and Lee YH: The antipsychotic agent chlorpromazine induces autophagic cell death by inhibiting the Akt/mTOR pathway in human U-87MG glioma cells. Carcinogenesis 34: 2080-2089, 2013. 
65. Kast RE: Glioblastoma chemotherapy adjunct via potent serotonin receptor-7 inhibition using currently marketed high-affinity antipsychotic medicines. Br J Pharmacol 161: 481-487, 2010

66.PierceKL,PremontRT andLef kowitzRJ: Seven-transmembrane receptors. Nat Rev Mol Cell Biol 3: 639-650, 2002.

67.Lappano R and Maggiolini M: GPCRs and cancer. Acta Pharmacol Sin 33: 351-362, 2012.

68. Neves SR, Ram PT and Iyengar R: G protein pathways. Science 296: 1636-1639, 2002.

69. Gonzalez-Maeso J: Anxious interactions. Nat Neurosci 13 524-526, 2010.

70. Meltzer HY: What's atypical about atypical antipsychotic drugs? Curr Opin Pharmacol 4: 53-57, 2004.

71. Blair DT and Dauner A: Extrapyramidal symptoms are serious side-effects of antipsychotic and other drugs. Nurse Pract 56, 62-64, 1992

72. Seeman P, Lee T, Chau-Wong M and Wong K: Antipsychotic drug doses and neuroleptic/dopamine receptors. Nature 261 717-719, 1976

73. Meltzer HY, Li Z, Kaneda Y and Ichikawa J: Serotonin receptors: their key role in drugs to treat schizophrenia. Prog Neuropsychopharmacol Biol Psychiatry 27: 1159-1172, 2003.

74. Fribourg M, Moreno JL, Holloway T, Provasi D, Baki L, Mahajan R, Park G, Adney SK, Hatcher C, Eltit JM, et al: Decoding the signaling of a GPCR heteromeric complex reveals a unifying mechanism of action of antipsychotic drugs. Cell 147: 1011-1023, 2011.

75. Weiner DM, Burstein ES, Nash N, Croston GE, Currier EA, Vanover KE, Harvey SC, Donohue E, Hansen HC, Andersson CM, et al: 5-hydroxytryptamine2A receptor inverse agonists as antipsychotics. J Pharmacol Exp Ther 299: 268-276, 2001.

76. Bymaster FP, Calligaro DO, Falcone JF, Marsh RD, Moore NA, Tye NC, Seeman P and Wong DT: Radioreceptor binding profile of the atypical antipsychotic olanzapine. Neuropsychopharmacology 14: 87-96, 1996.

77. Noguchi K, Herr D, Mutoh T and Chun J: Lysophosphatidic acid (LPA) and its receptors. Curr Opin Pharmacol 9: 15-23, 2009.

78. Sanchez T and Hla T: Structural and functional characteristics of S1P receptors. J Cell Biochem 92: 913-922, 2004.

79. Mills GB and Moolenaar WH: The emerging role of lysophosphatidic acid in cancer. Nat Rev Cancer 3: 582-591, 2003.

80. Bagnato $\mathrm{A}$ and Rosanò L: The endothelin axis in cancer. Int J Biochem Cell Biol 40: 1443-1451, 2008.

81. Clevers H: Wnt/beta-catenin signaling in development and disease. Cell 127: 469-480, 2006.

82. Yang L, Wu X, Wang Y, Zhang K, Wu J, Yuan YC, Deng X, Chen L, Kim CC, Lau S, et al: FZD7 has a critical role in cell proliferation in triple negative breast cancer. Oncogene 30: 4437-4446, 2011.

83. Lai SL, Chien AJ and Moon RT: Wnt/Fz signaling and the cytoskeleton: Potential roles in tumorigenesis. Cell Res 19: 532-545, 2009.

84. Wang K, Wang X, Zou J, Zhang A, Wan Y, Pu P, Song Z, Qian C, Chen Y, Yang S, et al: miR-92b controls glioma proliferation and invasion through regulating Wnt/beta-catenin signaling via Nemo-like kinase. Neuro Oncol 15: 578-588, 2013.

85. Gong $\mathrm{A}$ and Huang S: FoxM1 and Wnt/ $\beta$-catenin signaling in glioma stem cells. Cancer Res 72: 5658-5662, 2012.

86.Zhang K, Zhang J, Han L, Pu P and Kang C: Wnt/beta-catenin signaling in glioma. J Neuroimmune Pharmacol 7: 740-749, 2012

87. Scales SJ and de Sauvage FJ: Mechanisms of Hedgehog pathway activation in cancer and implications for therapy. Trends Pharmacol Sci 30: 303-312, 2009.
88. Jiang $\mathbf{J}$ and Hui CC: Hedgehog signaling in development and cancer. Dev Cell 15: 801-812, 2008.

89. Ingham PW and McMahon AP: Hedgehog signaling in animal development: Paradigms and principles. Genes Dev 15 3059-3087, 2001.

90.Wicking C, Smyth I and Bale A: The hedgehog signalling pathway in tumorigenesis and development. Oncogene 18: 7844-7851, 1999.

91.Beachy PA, Karhadkar SS and Berman DM: Tissue repair and stem cell renewal in carcinogenesis. Nature 432: 324-331, 2004.

92.Ruizi Altaba A, Mas C and Stecca B: The Gli code: An information nexus regulating cell fate, stemness and cancer. Trends Cell Biol 17: 438-447, 2007.

93. Vandercappellen J, Van Damme J and Struyf S: The role of CXC chemokines and their receptors in cancer. Cancer Lett 267: 226-244, 2008.

94. Strieter RM, Belperio JA, Phillips RJ and Keane MP: CXC chemokines in angiogenesis of cancer. Semin Cancer Biol 14: 195-200, 2004.

95. Strieter RM, Burdick MD, Mestas J, Gomperts B, Keane MP and Belperio JA: Cancer CXC chemokine networks and tumour angiogenesis. Eur J Cancer 42: 768-778, 2006.

96. Teicher BA and Fricker SP: CXCL12 (SDF-1)/CXCR4 pathway in cancer. Clin Cancer Res 16: 2927-2931, 2010.

97.Zhou Y, Larsen PH, Hao C and Yong VW: CXCR4 is a major chemokine receptor on glioma cells and mediates their survival. J Biol Chem 277: 49481-49487, 2002.

98. Ehtesham M, Winston JA, Kabos P and Thompson RC: CXCR4 expression mediates glioma cell invasiveness. Oncogene 25 2801-2806, 2006

99. Terasaki M, Sugita Y, Arakawa F, Okada Y, Ohshima K and Shigemori M: CXCL12/CXCR4 signaling in malignant brain tumors: A potential pharmacological therapeutic target. Brain Tumor Pathol 28: 89-97, 2011.

100. Girault JA and Greengard P: The neurobiology of dopamine signaling. Arch Neurol 61: 641-644, 2004.

101. Gemignani F, Landi S, Moreno V, Gioia-Patricola L, Chabrier A Guino E, Navarro M, Cambray M, Capellà G and Canzian F: Polymorphisms of the dopamine receptor gene DRD2 and colorectal cancer risk. Cancer Epidemiol Biomarkers Prev 14 1633-1638, 2005

102. Sarkar C, Chakroborty D, Chowdhury UR, Dasgupta PS and Basu S: Dopamine increases the efficacy of anticancer drugs in breast and colon cancer preclinical models. Clin Cancer Res 14: 2502-2510, 2008

103. Rubi B and Maechler P: Minireview: New roles for peripheral dopamine on metabolic control and tumor growth: Let's seek the balance. Endocrinology 151: 5570-5581, 2010.

104. Bellack AS: Scientific and consumer models of recovery in schizophrenia: Concordance, contrasts and implications. Schizophr Bull 32: 432-442, 2006.

105. Leucht S, Cipriani A, Spineli L, Mavridis D, Orey D, Richter F, Samara M, Barbui C, Engel RR, Geddes JR, et al: Comparative efficacy and tolerability of 15 antipsychotic drugs in schizophrenia: A multiple-treatments meta-analysis. Lancet 382 : 951-962, 2013

106. Ucok A and Gaebel W: Side effects of atypical antipsychotics: A brief overview. World Psychiatry 7: 58-62, 2008. 